\title{
Eleştirel gerçekçilik bağlamında Tevfik Fikret şiirine bakış
}

\section{Secaattin TURAL ${ }^{1}$}

\begin{abstract}
APA: Tural, S. (2020). Eleştirel gerçekçilik bağlamında Tevfik Fikret şiirine bakış. RumeliDE Dil ve Edebiyat Araştırmaları Dergisi, (Ö7), 272-279. DOI: 10.29000/rumelide.808697.
\end{abstract}

\section{$\ddot{\mathbf{O} z}$}

Sosyalist dünya görüşüne bağlı olarak gelişen toplumcu gerçekçiliğin temel sorunlarından biri de farklı bir dünya görüşüne sahip olan bir yazarın eserinin değerlendirilmesinde ortaya çıan sorunlardır. Toplumcu gerçekçi olmayan bir yazarın eserinin değerinin olmadı̆̆ı ve edebiyat dışı sayılması tehlikesi ünlü Marksist eleştirmen Georg Lukacs'ın temellerini attı̆̆ "eleştirel gerçekçilik" kuramıyla bir nebze olsun atlatılmıştır. Lukacs'ın, Tolstoy, Balzac gibi sosyalist bir dünya görüşüne sahip olmayan gerçekçi yazarların çevrelerinde ve toplumda gördükleri eşitsizlikleri, haksızlıkları, adaletsizlikleri, sınıf çatışmalarını hiç taraf gözetmeksizin, içten ve dürüst bir dille ve gerçekçi bir bakış açısıyla eserlerine yansıttığını söylemesi, Türk edebiyatı söz konusu olduğunda Tevfik Fikret’i hatırlamamıza yol açmıştır. Toplumcu gerçekçi eleştirmenlerimiz ona bu gözle baktığında hayli önemli sonuçların ortaya çıacağını söyleyebiliriz. Toplumcu gerçekçi olmayan bir yazarın da yaşadığı dönemin kusurlarını, bunalımlarını, çelişkilerini eleştirel gerçekçi bir bakış açısıyla eserlerine yansıtabileceği Fikret’in şiirlerine bakıldığında kendiliğinden ortaya çıkacaktır.

Anahtar kelimeler: Gerçekçilik, toplumcu gerçekçilik, eleştirel gerçekçilik, şiir, sosyalizm

\section{An overview of Tevfik Fikret's poetry in the context of critical realism}

\begin{abstract}
One of the main problems of socialist realism which is developing depend on the socialist woldview is, the emerging issues during the evaluation of a work of author who has a different worldview. The danger of considering the work of an author who is non-socialist realist, as unworthy and nonliterary was overcome a little bit by the "critical realism" theory that was generated by famous Marxist critic George Lukacs. Lukacs' expression of realist writers who don't have a socialist worldview like Tolstoy, Balzac, reject the inequality, unfairness, injustice, class conflict of their environment and society by an objective, sincere and honest wording and realist perspective led us to remember Tevfik Fikret in the case of Turkish literature. We can say that the significant results will be revealed, if the critics based on socialist realism regard Tevfik Fikret at this view. The ability of a non-socialist-realist writer can also reject the laws, the crisis, the conflicts of his life period by a critical realist perspective is revealed intrinsically when considering the Tevfik Fikret's poetry.
\end{abstract}

Keywords: Realizm, socialist realizm, crtical realism, poetry, socializm

Edebiyatımızda olduğu kadar düşünce dünyamızda da oldukça tartışmalı isimlerden biri olan Tevfik Fikret’in gerçekçi bir yönelimle eserlerini verdiğini söylesek herhalde bir takım itirazların olacağını peşinen kabul ederiz. Servet-i Fünun edebiyatı içinde değerlendirildiğinde bu hükmün oldukça tartışmalı olduğu aşikardır. Bunun yanında Fikret’in şiirlerinde toplumcu ögeler barındırdığını da

Prof. Dr., İstanbul Medeniyet Üniversitesi, Edebiyat Fakültesi, Türk Dili ve Edebiyatı Bölümü (İstanbul, Türkiye), secaattintural@yahoo.com, ORCID ID: oooo-0002-2923-6055 [Makale kayıt tarihi: 09.09.2020-kabul tarihi: 20.10.2020; DOI: 10.29000/rumelide.808697] 
ilave edersek söz konusu tartışmanın daha da büyüyeceğini söyleyebiliriz. Bu tür itirazların dayanak noktalarından birini aslında şairimiz de itiraf etmektedir. Fikret’i bu bağlamda bütüncül bir bakışa açısıyla Servet-i Fünun edebiyatı içinde değerlendirmek için kendi ifadelerine başvuralım:

"İhtimal ki hissimde yanılıyorum. Edebiyat-ı hâzıranın bütün inceliklerine, güzelliklerine, sanatlarına mukabil bir noksanı var ki telafisi öyle zannederim, üdebâ-yı hâzıraya nasip olmayacak....Bu bir noksandan ziyade bir hastalığa benziyor..Edebiyat-ı hazıra nakıs değil, hasta:ince, sari bir hastalık ki kurbanının bütün uruk-ı hayatında mündemiç, sanki hasta bizzat hastalıktır." (Kaplan: 1987, 43.)

$\mathrm{Bu}$ ifadeye dillerinin sadelikten uzak oluşu ve o güne kadar edebiyatımızda görülmeyen imajlar kullanmalarıyla toplumdan kendilerini soyutlamış oldukları suçlamalarının da eklenmesiyle portre tamamlanmış olur. Peki söz konusu ifadesi ve döneminde yapılan eleştiriler Tevfik Fikret’i hakikaten toplumdan soyutlanmış, ferdi ıstıraplarını dile getiren, gerçeklerden kaçmak için hayali diyarlara iltica eden, toplumsal hiçbir soruna değinmeyen bir şair olarak değerlendirmemize yetecek midir? Tabii ki ortalama edebiyat tarihi bilgisine sahip bir kişi bile Fikret'i bu yönlerden diğer Servet-i Fünun şairlerinden ayrı bir yere koyacaktır. Zaten yazının daha en başında belirttiğimiz gibi Fikret’i bugün bile olumlu olumsuz eleştirilerin odağında kılan da bu ayrıntıda gizlidir. Fikret daha sonra ayrıntılı olarak değineceğimiz gibi verdiği eserler ve hayat hikayesi ile Türk düşünce ve edebiyat dünyasında yalnızca şairliği ile değil, politik ve ideolojik kimliği ile de tanımlanmaktadır. Muhafazakar çevrelerin Tarih-i Kadim ve Haluk’un Amentüsü gibi şiirleri dolayısıyla reddettiği Fikret, sosyalist ve laik çevrelerde ise aynı şiirler dolayısıyla idol olarak kabul edilmiştir. Buradaki ayrışma noktası sosyalist eleştirmenlerin tavrında gizlidir. Çoğu toplumcu gerçekçi eleştirmen Fikret’in din karşısındaki olumsuz tavrını onu kabullenmek için yeterli bir sebep sayarken, Türk sosyalist hareketinin önemli bir ismi olan Hikmet Kıvılcımlı onu burjuva bir şair sayarak Servet- Fünun edebiyatını tümüyle hasta olarak kabul eder ve onun çağının gerçeklerine sırt çevirdiğini iddia eder. (Kıvılcımlı, 1989) Kıvılcımlı için Fikret ve arkadaşları diyalektik materyalizmi anlayamamış, çevrelerine duyarsız, dekadans, melankolik, hasta tiplerdir ve eserleri de bu hastalıklı ruh hallerini yansıtır. Fakat şunu söylemeliyiz ki Kıvılcımlı'nın bu tespitlerine Türk sosyalistleri itibar etmemiş ve Fikret’in yaşadığı günün şartları içinde söz konusu diyalektik düşünceyle temas edemeyeceğini belirterek onun şiirlerindeki dini ve metafizik düşünceye karşı çıkmasını ve "Balıkçılar", Verin Zavallılara" gibi şiirlerindeki halkın içinde bulunduğu yoksulluğa vurgu yapmış olmasını, "Sis" şiirinde ise dönemin iktidarına yönelttiği sert eleştiriyi yeter sebep görerek Kıvılcımlı'nın eleştirilerine karşı çımışlardır. Buna örnek olarak Sabiha Sertel'in "İlericilik ve Gericilik Kavgasında Tevfik Fikret" adlı bir kitap yazdığını verebiliriz. Sertel, Akif-Fikret tartışmalarından başlayarak Fikret'în ilerici bir şair sayacak örnekler üzerinden giderek, sosyalist olmasa bile dinin karşısına insaniyetçiliği koymasıyla her türlü sınıf, ırk, din farklılığına karşı çıkmasıyla takdir edilecek bir tavır koyduğunu söyler. Aslına bakılırsa Fikret'ten diyalektik materyalizmi benimsemiş toplumcu-sosyalist bir şiir beklemek hakikaten anlamsızdır. Bunun yanında bir diğer nokta da Fikret’in sosyalizm temayülleri olduğuna, fakat sosyalizmi tanıması mümkün olmadığı için insaniyetçi, adalet ve eşitlik peşindeki romantik sosyalizme yakın olarak tanımlayan Sertel gibi sosyalist aydınların, Fikret’in toplumcu gerçekçi olarak değil eleştirel gerçekçilik içinde değerlendirilebilme imkanını kaçırmış olmalarıdır. Aslında Ahmet Oktay bu noktaya işaret etmiş, fakat bu yönde bir adlandırmada bulunmamıştır. Oktay, Mehmet Kaplan'dan yaptığı şu alıntıyla meseleye yaklaşmıştır: "Hayattan nefret duygusu, teferruatına kadar işlenmiş bir tasvir ve musiki Rübab-ı Şikeste'nin başlıca hususiyetlerini teşkil ediyordu. Sis ile Tevfik Fikret esas temini ve sanat vasıtalarını içtimai plana nakletmiştir:”(Oktay, 1986:396) Oktay için önemli olan Fikret’in yaşadığı çağ içindeki açmazları dile getirmesi ve kendi deyişiyle hastalıklı, marazi bir edebiyat ortaya koymalarından kendilerinin bile rahatsız olması çelişkilerin farkında olmaları yönüyle gerici değil ilerici bir tavrın 
işaretidir. Bu aynı zamanda kendilerinin de içinde bulunduğu sınıfın, yani burjuvazinin çöküşünü de gösterdiği için de diyalektiğe uygundur Oktay için.

Toplumcu geçekçiliğin sosyalist bir dünya görüşü içinde toplumdaki adaletsizliklerin temeli olarak sınıf çatışmasını öne çıkarmasını ve ezilen kesimlerin sözcülüğünü üstlenerek ideal sosyalist tipler yaratmak suretiyle sosyalist devrimin gerçekleşeceğine dair ümitleri diri tutan eserler üretilmesine dayandığını biliyoruz. Buradaki temel sorun ise sosyalist olmayan bir yazarın söz konusu toplumsal gerçekleri yansıtıp yansıtmadığıdır. Bu sorunun cevabı Marx ve Engels’in, Fransız aristokrat kültürünün kapitalizmin gelişmesiyle burjuva sınıfının lehine ortadan kaldırıldığını gerçekçi bir gözle yansıttığı için monarşi yanlısı Balzac'a olan övgülerinde saklıdır. Onlara göre Balzac'ı büyük yapan şey, gerçeklik kendi kişisel görüşlerine, umutlarına ve isteklerine karşı gitse de onu betimlemedeki sarsılmaz dürüstlüğüdür. (Lukacs, 1987:31) Fikret’in Balzac gibi sınıfsal bir ayrımın farkında olmadığını söylemeliyiz. Çünkü Batıda olduğu gibi keskin çizgilerle sınıflara ayrılmamış Osmanlı toplumunda Fikret gibi yazarlarımızı nispeten burjuva diyebileceğimiz bir sınıfa ait sayabiliriz. Yalnız burada burjuvayı yalnızca orta sınıf anlamında kullandığımızı hatırlatmak gerekir. Bugünkü beyaz yakalılar tabiri aslında daha uygundur. Eğitimli, aydın diye tabir edebileceğimiz orta halli bir bireydir kastettiğimiz. Fikret’in sosyalist bir aydın-yazar da sayamayacağımıza göre toplumdaki adaletsizliklere, haksızlıklara, halkın içinde bulunduğu yoksulluğa ve yoksunluğa, politik başkaldırıya dair şiirlerini eleştirel gerçekçilik bağlamında değerlendirmenin daha doğru olacağı kanaatindeyiz.

Fikret’in Balıkçlar şiiri yoksulluk içindeki bir balıkçı ailesinin dramını anlatması bakımından söz konusu eleştirel gerçekçi tutum için önemli bir örnek metindir.

Bugün açız yine evlatlarım, diyordu peder

Bugün açız yine; lakin yarın ümid ederim,

Sular biraz daha sakinleşir...ne çare, kader!

mısralarıyla başladığı şiirinde giderek yükselen bir tonda trajik bir öyküyü anlatmaya başlar. Ana babası hasta olan çocuk eve ekmek getirmek için kendisi kadar çelimsiz ve bakımsız bir tekneyle balığa çıkacaktır. Babası çaresizce çocuğu fırtınanın koptuğu denize gönderirken ölümün mukadder olduğunu da bilir. Hasta olan anası denize bakarak ölüme yaklaşırken çocuk da dalgalarla boğuşarak ölür. Şiirde açlı̆̆ın, sefaletin mahkum ettiği yoksul insanların trajedisini dillendiren Fikret, hayatın içinde olabilecek bir manzarayı bize çizmiştir. Kimileri için Fransız edebiyatından bir kopya, ya da bir resimden ilhamla açıklansa bile, yine de gerçekçi bir anlatım söz konusudur şiirde. Burada fakirliğin pençesinde kıvranan bir ailenin dramını verirken takındığı tavır toplumcu değil, eleştireldir. Bu tabloyu canlandırırken ezilen bir sınıfı anlatmaktan çok merhamet duygularıyla yaklaştığı romantik bir tavır söz konusudur. Toplumdaki sınıfsal çatışmaya ve bundan çıkacak olan devrimci bir söyleme yönelmemesi eleştirel gerçekçilik içinde değerlendirmemize yol açmaktadır. Yine Nesrin şiirinde de benzer biçimde toplumsal sefalete çocuk safiyetini katarak insanları merhamete davet eder.

Hanım ben hamarat bir çocuğum

Nineciğim öldü, babam yok, bana bir vicdansız

Para teklif ediyor...Ben size kurban olurum

Beni reddetmeyiniz, saklayınız...Hizmetten

Hiç yorulmam...Beni tahlis ediniz zilletten... 
Daha önce de belirttiğimiz gibi Fikret’in sosyal hayattaki sefalet ve ahlak yoksunluğu karşısında göstermiş olduğu tavır romantik bir düzeyde kalsa da ezilen kitlelere sınıfsal açıdan yaklaşmasa da gerçekçiliğe bir anlamda göz kırpmaktadır. Fikret, bu anlamda sınıf çatışmasını göz ardı etmesi, toplumun merhametinden başka bir çözüm arayışına girmemesi bakımından eleştirel gerçekçilik içinde değerlendirdiğimiz bir tavrın sözcücüdür. Halbuki toplumcu gerçekçi edebiyatın en büyük özelliği ortaya çıkan resmi göstermenin yanında çözümü de beraberinde işlemesidir.

Eleştirel gerçekçi tutum bir anlamda edebiliğe daha uygun bir anlatım tarzıdır. Lukacs'ın Gorki yerine Balzac ve Tolstoy'u tercih etmesi de bunun bir göstergesidir. Tevfik Fikret’in şiirinde diğer eleştirel gerçekçilerden farklı olarak gerçekliği zayıflatan en önemli unsur, çizdiği tabloların oldukça kitabi kalmalarıdır diyebiliriz. Bu nedenle doğrudan doğruya hayattan alınmamış olmaları aynı motiflerin tekrarlanmasına yol açmış ve şiirsel söylemi zayıflatmıştır. Yukarıdaki iki şiirde de çocuk imgesinin stereotiplere dönüşmesi bunun bir göstergesidir. Aynı imge Hasta Çocuk şirinde de kendisini göstererek merhamet duygularını uyandırmak için bir vasıta olarak kullanılmıştır. Fakat söz konusu şiir ferdiyetten toplumsala bir açlımı içermediği incelememizin dışında kalmıştır.

Fikret, Verin Zavallhlara adlı şiirinde ise söz konusu toplumsal mesaja yoğunlaşmıştır. Bir zelzele sonrasındaki köyün harap halini tasvir ederken oldukça gerçekçi bir tutum sergilemiş ve "Verin şu dullara, yoksul kalan şu eytama/ Verin enînine gayet, şu bir yığın beşerin!” diyerek toplumun vicdanına seslenirken oldukça gerçekçi bir tablo çizer:

$$
\begin{aligned}
& \text { Harab-ı zelzele bir köy...Şu yanda bir çatının } \\
& \text { Çürük direkleri dehşetle fırlamış öteden } \\
& \text { Çamur yığıntısı şeklinde bir zemin katının } \\
& \text { Yıkık temelleri manzur, uzakta bir mesken } \\
& \text { Zemine doğru eğilmiş, hemen sükut edecek } \\
& \text { Önünde bir kadın...Of, artık istemem görmek }
\end{aligned}
$$

Fakir ve ücra bir Anadolu köyünün depremden sonraki sefaletini işleyen bu şiire dikkatli bakıldığında deprem öncesinin tasvirinin de benzer kelimelerle ifade edilebileceğini söylemeliyiz. Ancak Fikret ve çağdaşlarının Anadolu'yu yakından tanımamaları ve ancak gazete haberleri vasıtasıyla bu tanışmanın gerçekleşmesi şiirin olası bir eleştirel gerçekçi metne dönüşmesini engelleyen en önemli nedenlerdendir. Söz konusu tasvirin köy hayatını yakından tanıyan bir şairin kaleminde farklı işleneceğini ve eleştirel gerçekçilikten toplumsal gerçekçiliği hazırlayan bir boyuta yükseleceğini söyleyebiliriz. Fikret’te ise diğer Servet-i Fünuncularda olduğu gibi gibi romantik duyuş tarzı içinde bir gerçekçilik söz konusudur.

“Ramazan Sadakası”nda da benzer bir söylemi görüyoruz.

Efendiler ne olur, ben fakîrim işte”...sükut.

Efendiler acıyın" Pür vakâr-ı bî-ârâm

Efendiler geçiyor, yavrucak soluk, mebhût

Nazarlarında hazin bir eda-yı istirham/

Çolak eliyle verir her geçen hayale selam 
Tevfik Fikret, bu hazin mısralardan sonra şiirin sonunda "Sizindir işte, verin susturun bu hasta sesi" diyerek toplumun duyarsızlığına karşı isyan etmektedir. Fikret bu şiirinde toplumcu edebiyatın söylemine bir nebze olsun yaklaşabilmiştir. Çocuğun soğukta titreyerek sadaka dilenmesi aslında toplumun suçudur diye yorumlayabileceğimiz bir önermeye sahip olan şiir hastalığın kaynă̆ının toplumda olduğunu ima etmesi bakımından önemlidir. Burada merhamet duygusunu da aşan bir tavrın ortaya çıması eleştirel gerçekçiliğin bir adım öne çıkmasını da sağlamıştır. Toplumdaki eşitsizliğin ve sömürünün kaynağına dair yapılan ima diğer şiirlerine nazaran gerçekçi edebiyat anlayışına daha uygundur. Yalnız burada yine çocuk imgesinin başat unsur olduğunu da gözden kaçırmamalıyız. Toplumdaki yoksulluk ve sefalet "çocuk" imgesinde kendisini ortaya koymaktadır. Bunda çocuğun bizatihi kırılganlığı, edilgenliği, güçsüzlüğü temsil etmesinin rolü olsa gerek. Fakat Fikret gözünü hayatın içine çevirebilseydi Akif'in daha sonra çizeceği sosyal hayatın aksayan yanlarından daha farklı imgeler biriktirebilirdi. Hikmet Kıvlcımlı'nın onun hakkındaki eleştirileri bu yönden değerlendirilebilir. Kıvılcımlı ondan burjuva merhameti değil, toplumda bin bir kılıkta tezahür eden sömürü ve acımasızlığı ortaya koyan hayat sahnelerini beklemiştir.

Tevfik Fikret’in yaşadığı dönemin sosyal, siyasi, ideolojik dünyasının çelişkilerini, dönüşümlerini Kıvılcımlı'nın iddia ettiği gibi kavrayamamış olduğunu söyleyemeyiz. Onun özellikle Tarih-i Kadim, İnanmak İhtiyacı,, Haluk'un Amentüsü, Sis, Han-ı Yağma gibi şiirleri içinde yaşadığı toplumun değerler hiyerarşisinin nasıl değiştiğinin farkında olduğunu göstermesi bakımından önemlidir. Tanzimattan bu yana yaşanan medeniyet krizinin getirdiği bunalımların deist, hatta ateist bir tavra dönüştüğünü, Türk aydınının özellikle dini değerlere şüpheyle yaklaştığını, sorguladığını, hatta bir Jöntürk kimliğini nasıl edindiğini biliyoruz. Siyasi anlamda başlayan Batılılaşmanın kültür ve medeniyete evrilmesiyle sonuçlanan bu değişimin müşahhas kimliği Tevfik Fikret’tir. Bir Lahza-i Tahattur adlı şiirinde bütün kötülüklerin kaynă̆ı olarak gördüğü II. Abdülhamid'e yapılan suikastı”Ey şanlı avcı, dâmını bî-hûde yere kurmadın/ Attın...Fakat yazıklar ki vurmadın!” diyerek alkışlayan Fikret, bütün nefretini ise Sis şiirinde dökmüştür. "Sarmış yine âfâkını bir dûd-ı muannid/Bir zulmet-i beyzâ ki pey â pey mütezayid” diye başlayan şiirinde dönemin iktidarına İstanbul'u sembol alarak oldukça yüksek tonda eleştiriler getirmiştir. Tanpınar bu şiiri Abdülhamid döneminin romanı olarak tanımlamıştır. "Sis bir infial anının herhangi bir istiare ile ifadesi değildir. Belki Abdülhamid devrinin bir hasta odasını andıran vehimli İstanbul'unun geniş bir visionda toplanmış bütün bir romanıdır. $\mathrm{Bu}$ bir manzume değil, geniş, korkunç ve zalim bir bedduadır"(Tanpınar, Edebiyat Üzerine Makaleler, s.288) diyen Tanpınar hayli ilginç bir yorumda bulunur. Mehmet Kaplan 1900 yllından sonra içine düştüğü ruh halinin Fikret’in kötümserliğinin artması neticesinde ortaya çıktığını söylediği bu şiir yazıldığı dönemin sosyal, siyasi havasının şair üzerindeki olumsuz etkilerinin izlerini taşıması bakımından mühim olmasının da ötesinde eleştirel gerçekçi bir tutum sergilemesi bakımından hayli dikkat çekicidir. Hikmet Kıvılcımlı gibi sosyalist aydınların görmezden geldiği, Sabiha Sertel ve günümüz sosyalist aydınlarının ise II. Abdülhamit dönemine getirdiği eleştiriler nedeniyle Fikret’in şaheseri saydığı bu şiir gerçekten de şairimizin eleştirel gerçekçiliği de aşan bir politik bilinçle kaleme aldığı bir metin olma özelliği taşımaktadır. Fikret’e kadar güzelliğin, sanatın, ihtişamın sembolü olmuş İstanbul, bu şiirle beraber kuvvetli bir nefret objesi haline gelir. Türk edebiyatında İstanbul ilk defa Sis ile menfur ve mel'un bir şehir olarak ele alınmıştır.(Kaplan, Şiir Tahlilleri, s. 105) Mehmet Kaplan’ın İstanbul dekoru içinde dönemin siyasi iktidarına yönelttiği bakışları Jöntürk kimliğine bağladığını hatırlamakla beraber metnin söyleminin dışına çlkmamak için söz konusu yorumlara sadece değinmekle geçeceğiz. Amacımız şiirin tahlilinden çok, Fikret’in içinde bulunduğu sosyal, siyasi hadiselere yabancı kalmadığına dikkat çekmektir. Şiire ismini veren sis sembolü siyasi bir imaj olması bakımından hayli önemlidir. Daha önce de belirttiğimiz gibi bu şiir, eleştirel gerçekçiliği de aşan bir siyasi metin olarak yorumlandığında, Servet-i Fünun duyarlılığından ayrı bir tutumu içermesi 
bakımından da dikkat çekicidir. Romantik duyarlılığa dayanan Servet-i Fünun neslinin duyuş tarzı, bu şiirde toplumsal gerçekçiliği barındıran imajlarla zenginleştirilmiştir. Çoğu araştırmacının iddia ettiği melankoliden beslenen bedbin bir ruh halinden ziyade politik bir karşı çıkış metni olarak okumanın daha doğru olacağı kanaatindeyiz. Zira II. Abdülhamid döneminden sonra dünya görüşü olarak daha yakın olduğu ve bir Jöntürk hareketi olan İttihat ve Terakki Partisi'nin uygulamış olduğu yanlış politikalara da aynı sertlikte muhalefet etmesi Fikret'in muhalif kimliğini göstermesi bakımından önemlidir. Han-ı Yağma adlı bu şiirde Sis'e benzer bir atmosfer çizilmiştir.

Bu sofracık, efendiler ki iltizama muntazır

Huzurunuzda titriyor şu milleti,n hayatıdır.

Şu milletin ki muztarib, şu milletin ki muhtazır!

Fakat sakın çekinmeyin, yiyin, yutun hapır hapır...

Yiyin efendiler yiyin, bu han-ı iştiha sizin;

Doyunca, tıksırınca,çatlayıncaya kadar yiyin!

Görüldüğü gibi oldukça yüksek dozda eleştirel bir tavırla seslendiği çevre, Abdülhamid dönemine ait değildir. Büyük bir ümit ve coşkuyla karşılanan II. Meşrutiyet'in kurucu iktidar olan ve Fikret'in Sis'ten sonra Rücu adlı şiirini kaleme almasını sağlayan İttihat ve Terakki Partisi'nin politikalarını eleştiren bir şiir olan Han-ı Yağma, eleştirel gerçekçilikten toplumsal gerçekçiliğe geçemese de imalarda bulunması yönünden hayli ilgi çekici mısralara sahiptir.

Bu harmanın gelir sonu, kapıştırın giderayak!

Yarın bakarsınız söner bugün çatırdayan ocak!

Bugün ki mideler kavi, bugün ki çorbalar sıcak,

Atıştırın, tıkıştırın, kapış kapış, çanak çanak...

Yiyin efendiler yiyin, bu han-ı pür-neva sizin;

Doyunca, tıksırınca, patlayıncaya kadar yiyin!

Daha önce belirttiğimiz gibi toplumda meydana gelen haksızlıkları, sömürüyü, adaletsizliği, eşitsizlikleri sadece tespit etmekle yetinen eserlere eleştirel gerçekçi, bütün bunların yanında bu olumsuzların biteceğine dair ümit besleyen ve mazlumların bir gün galip geleceğine dair imalarda bulunan eserlere ise toplumsal gerçekçi denilmektedir. Bu şiir bizce Sis şiiri ile bağlantılı değerlendirildiğinde, çoğu araştırmacının tersine Fikret'in bedbin, kötümser, melankolik ruh halini değil, sosyal ve siyasi meseleler karşısında duyarlı ve muhalif kimliğini göstermesi bakımından önemli ip uçları vermektedir. Fikret Rücu şiirinde nası ki II. Meşrutiyet’in gelişiyle dönemindeki çoğu aydının yanlışına düşerek meseleyi Abdülhamid’in gidişinin getireceği mesut günlere bağlama yanlışına düşmüşse, İttihat ve Terakki Partisi'nin gelişiyle hiç bir şeyin değişmeyeceğini anlayan bir ayrın profiline yükselmiştir diyebiliriz. Fakat onun meselenin "iktidar" denen kavramın sosyolojik ve felsefi yönlerine vakıf olduğunu söyleyecek değiliz. Yalnızca haksızlıklar karşısında duyarlı bir aydın tavrından söz edebiliriz. Bu da onun en baştan bu yana söylemeye çalıştığımız romantik duyarlılı̆̆ının bir sonucudur. Nasıl ki haksızlığa karşı çıkışı, sömürünün nedenlerini anlamasını sağlayamamışsa, iktidarın el değiştirmesinin sömürü araçlarının el değiştirmiş olduğunu görememesiyle sonuçlanmıştır. Zaten o dönemin aydınından da bu bilinci beklemek haksızlık olur. Burada olumlu ya da olumsuz bir yargıda bulunmak yerine Hikmet Kıvılcımlı'nın iddia ettiği gibi kendi ferdi ıstıraplarıyla meşgul bir burjuva yazarı kimliği barındırmadığını söylemek istiyoruz. Bu anlamda 
Fikret'in şiirleri hayattan manzaraların yanında, yaşanan adaletsizliklerin, eşitsizliklerin, sefaletlerin çözümünü sadece yönetim, iktidar değişiminden ibaret gören kısıtlı bir dünya görüşünün altını çizmek zorundayız. Zira II. Meşrutiyet'in ilanından sonra 31 Mart vakası bahane edilerek II. Abdülhamid'in tahttan uzaklaştırılmasıyla kendi ifadesince zulmün ve haksızlıkların bitmediğini görmesi buna bir örnektir. Han-ı Yağma şairi zaten bu noktada toplumcu gerçekçi değildir. Çünkü bu teoriye göre sinıf çatışmalarının temelinde ekonomik güce sahip olma savaşı yatar ve toplumun sosyo-ekonomik yapısı üst yapıyı belirler. Dolayısıyla sosyalist devrim ezilenlerin, işçi ve köylü anlamında söylüyoruz üretim araçlarını ele geçirmeleriyle oluşur. Halbuki Fikret'in bu yönde bir kuramı zaten bildiğini ve savunduğunu söyleyemeyiz. O günün şartlarında mümkün olmayan bu bilinç, eleştirel gerçekçiliğin aynasında kırık da olsa kendisini bu tür toplumcu temaların kullanılmasıyla gösterebilir.

Bunun yanında Tarih-i Kadim şiirinde "Din şehid ister asuman kurban/her zaman her tarafta kan, kan, kan” diyerek dünyadaki bütün kötülüklerin, sefaletlerin, adaletsiliklerin kaynağının dinler olduğunu ileri sürerken, yine "Haluk'un Amentüsü"nde "Bir kudret-i külliye var ulvî ve münezzeh,/Kudsî ve muallâ, ona vicdanla inandım/" diyen şair, dinlerin insanlığın kardeşliğini reddettiğini, şeytanın, meleğin, cinin olmadığını, aklın, bilimin her türlü dini düşünceyi yok edeceğine olan inancını belirtir. Tarih-i Kadim'e Zeyl şiiri ise Mehmet Akif'in şiirine verdiği cevaptır. Fikret bir yandan da toplumcu gerçekçi edebiyatın dayanmış olduğu en önemli temel olan diyalektik materyalist felsefenin ve sosyalizmin metafiziği diyebileceğimiz "hayat dini”ni öne çıkararak dönemin aşırı cezrî Batıcılarının, Jöntürklerin sözcülüğünü de üstlenmiş gibidir.: "Din-i hak bence, bugün dini hayat!/Sen ne dersin buna ey Molla Sirat!" demesi bunun göstergelerindendir. Fikret’in "din” hakkındaki görüşlerinin şiirlerine yansıması, ayrı bir çalışmanın konusu olacak kadar geniş olacağı için biz yalnızca eleştirel gerçekçilik bağlamında bu kadar bilgi vermenin yeteceğini düşünüyoruz. Bu konuya değinme sebebimiz ise toplumcu gerçekçilerimizin Fikret'le kurduğu bağın sadece dini düşünceye yönelttiği olumsuz bakış açısından kaynaklandığına dair inancımızdan kaynaklanmaktadır. Bunun örneklerini yazımızın başlarında vermeye çalıştık. Toplumcu gerçekçi yazarlarımızın benzer temaları dile getirmesine rağmen Mehmet Akif başta olmak üzere bazı yazarlarımızı görmezden gelme sebebinin de dine bakışlarındaki farklılıktan gelmektedir. Toplumcu gerçekçi bir yazarın bu tutumunun haklı nedenleri olduğunu bilsek de -diyalektik materyalizm ve sosyalizmin bu kuram için vaz geçilmezliği gibi-hasımlık yerine bir hısımlık kurulsaydı belki de eleştirel gerçekçilik daha iyi anlaşılabilirdi. Eleştirel gerçekçilik, hem Tevfik Fikret’i Hikmet Kıvılcımlı gibi sosyalist aydınların burjuva şairi diye küçümsemesinin, hem Sabiha Sertel gibi sosyalistlerin dine bakışla sınırladığı bir Fikret portresinin önüne geçebilir, hem de Mehmet Akif'in toplumcu temaları şiirinde nasıl başarıyla kullanabildiğinin farkına varılmasını sağlaması bakımından önemlidir. Türk edebiyatının AlafrangaAlaturka, Doğu-Batı izleğinden "ilerici-gerici” temel izleğine evrilmesinde Fikret’in rol model olmasının tamamıyla bu tutumun bir sonucu olduğunu düşünebiliriz.

Sonuç olarak diyebiliriz ki diğer Servet-i Fünucular kadar olmasa da Fikret’in de gerçeklerden hayali alemlere kaçışı, bedbinlikleri, marazilikleri, sanata sığınması, bu belirsizliği vurgulaması, içinde yaşamış olduğu sosyal-siyasi ortamı yansıttı ğı için nisbeten gerçekçi diyebiliriz..Başka bir deyişle Batılı bir hayat tarzını benimseyen ama geleneksel bir dünyada yaşamak zorunda kalmalarının sonucu olarak yorumlayabileceğimiz bu dilemma aslında oldukça gerçekçi bir tutumdur. Hayatı kitaplardan öğrenen bir neslin temsilcisi olan Tevfik Fikret’in hayat manzaralarını resim ve kitaplardan süzülen bir duyguyla vermesi de bizce gerçekçi bir tavırdır. Hepsinden önemlisi ise, merhamet duygusunun eşliğinde her türlü haksızlığa karşı romantik de olsa eleştirel bir gözle muhalif bir tavır takınabilmesi onun hayatının ve şiirinin ana unsurlarından biridir. 


\section{Kaynakça}

Kaplan, M. (2016). Tevfik Fikret. İstanbul : Dergah.

Kaplan, M. (1976). Türk Edebiyatı Üzerine Araştırmalar I. İstanbul : Dergah.

Kıvılcımlı, H. (1978). Edebiyatı Cedide’nin Otopsisi. İstanbul : Çağrı.

Lukacs, G. (1987). Avrupa Gerçekçiliği. İstanbul : Payel.

Oktay, A. (1986). Toplumcu Gerçekçiliğin Kaynakları. İstanbul : BFS.

Sertel, S. (1969). İlericilik-Gericilik Karşısında Tevfik Fikret, İstanbul.

Tanpınar, A. H. (1998). Edebiyat Üzerine Makaleler, Haz. Zeynep Kerman. İstanbul : Dergah.

Tevfik Fikret (2005). Rübab-ı Şikeste, Haz. Abdullah Uçman. İstanbul : Çağrı.

Tural, S. (2014). Eleştirel Gerçekçilik Bağlamında Mehmet Akif Şiirine Bakış, RumeliDE Dergisi, S. 1, S.2O-25 